\title{
Frequency and time domain modeling and power output for a heaving point absorber wave energy converter
}

\author{
Jeremiah Pastor $\cdot$ Yucheng Liu
}

Received: 8 January 2014/ Accepted: 8 April 2014/Published online: 25 April 2014

(C) The Author(s) 2014. This article is published with open access at Springerlink.com

\begin{abstract}
This paper presents, assesses, and optimizes a point absorber wave energy converter (WEC) through numerical modeling, simulation, and analysis in both frequency and time domain. Wave energy conversion is a technology especially suited for assisting in power generation in the offshore oil and gas platforms. A linear frequency domain model is created to predict the behavior of the heaving point absorber WEC system. The hydrodynamic parameters are obtained with AQWA, a software package based on boundary element methods. A linear external damping coefficient is applied to enable power absorption, and an external spring force is introduced to tune the point absorber to the incoming wave conditions. The external damping coefficient and external spring forces are the control parameters, which need to be optimized to maximize the power absorption. Two buoy shapes are tested and a variety of diameters and drafts are compared. Optimal shape, draft, and diameter of the model are then determined to maximize its power absorption capacity. Based on the results generated from the frequency domain analysis, a time domain analysis was also conducted to derive the responses of the WEC in the hydrodynamic time response domain. The time domain analysis results allowed us to estimate the power output of this WEC system.
\end{abstract}

Keywords Wave energy technology · Energy conversion - Numerical modeling and simulation . Frequency and time domain

\footnotetext{
J. Pastor · Y. Liu ( $₫)$

Department of Mechanical Engineering, University of Louisiana at Lafayette, Lafayette, LA 70504, USA

e-mail: yucheng.liu@ louisiana.edu

J. Pastor

e-mail: jeremiah@louisiana.edu
}

\section{Introduction}

As concerns about rising fossil fuel prices, energy security, climate change, and environmental pollution, renewable energy can play a key role in producing local, clean, and inexhaustible energy to supply global growing demand for electricity. Among common renewable energy sources, the waves generated in gulfs and oceans reflect a huge body of untapped renewable energy source, which owns a large amount of energy potential that can be transformed into electricity. Nowadays, the wave energy has led to promising technologies and commercial deployment [1].

Based on the authors' previous study and following a complete approach of system design, modeling and simulation, parametric study, and optimization, it was found that among different types of wave energy conversion devices, a point absorbing wave energy converter (WEC) with a direct drive power take-off (PTO) system is most efficient and beneficial in converting the low-speed oscillating motion of ocean waves [2]. The point absorbing WEC reflects a simple but robust technology, which consists of buoys or floating bodies to capture the wave's heaving motion. In a point absorbing system, buoys move through a single degree of motion with the ocean waves, driving swing arms that turn a rotary generator. This can then deliver needed power to the platform while releasing zero emissions to the atmosphere. Ocean waves apply large forces at slow speeds, and direct drive point absorbing systems are well suited to capture energy in these conditions. Comparing to other types of WECs (attenuators, terminators, etc.), the point absorber is relatively small in size and often used in arrays, where multiple devices are attached in series or parallel to capture energy in a large amount. It can be used in offshore for various depths of 
water. This aspect makes such system ideal to configure in relatively close proximity to where the power is needed.

Due to the immense potential and prospect of wave energy technology, a number of wave conversion devices have been designed and analyzed by researchers. McCormick and coworkers presented a pneumatic WEC system [3] and a self-propelled backward-bent duct wave energy system [4]. Tests of the pneumatic WEC system had been conducted with the mount at two depths to vary the natural oscillating frequency of the water column. The maximum electrical power output of the system was approximately $90 \mathrm{~W}$ in the monochromatic waves. In the self-propelled backward-bent duct system, a WEC subsystem was needed to provide parasitic energy to self-propel the presented system. Weinstein et al. [5] outlined a project of developing the Makah Bay pilot offshore power plant, which used AquaEnergy's point absorber wave energy conversion device-AquaBuOY. The device represented the next generation of the technology that combines the Swedish Hose-Pump and the IPS Buoy technologies to generate clean energy from ocean waves. Numerical modeling and optimization were performed on this device. Henderson [6] described the hydraulic power take-off system employed in the Pelamis WEC. The process of the system's development was presented, including simulation and laboratory tests at $1 / 7$ th and full scale. Results of efficiency measurements were also presented. Falcao [7] presented a general method of modeling oscillating-body WECs with hydraulic power take-off and gas accumulator. Special attention was paid on power take-off performance and design, and on the control of the system. Margheritini et al. [8] described concept of the sea slot-cone generator (SSG) WEC and the studies behind the process that leaded to the construction of such wave energy conversion system. The pilot plant was an on-shore full-scale module in three levels with an expected power production of $320 \mathrm{MWh} /$ year in the North Sea. Ruellan et al. [9] presented design methodology for a SEAREV WEC and described the operating principle associated with such WEC. In their design, two conversion technologies intended to transform wave energy into electricity were discussed. A unique design methodology for the all-electric conversion chain was therefore developed around several distinct control modes, including one featuring power leveling. Elwood et al. [10] presented an overview of the SeaBeavl project which began in the fall of 2006 and culminated in the ocean testing of a $10 \mathrm{~kW}$ direct drive wave energy conversion system in the fall of 2007. A system design approach was used to develop the taut-moored dual-body wave energy converter concept with the detailed design focused on production and ease of maintenance. Sheng and Lewis [11] conducted a pure numerical simulation in time domain for assessing the power capture capacities of wave energy devices. In the

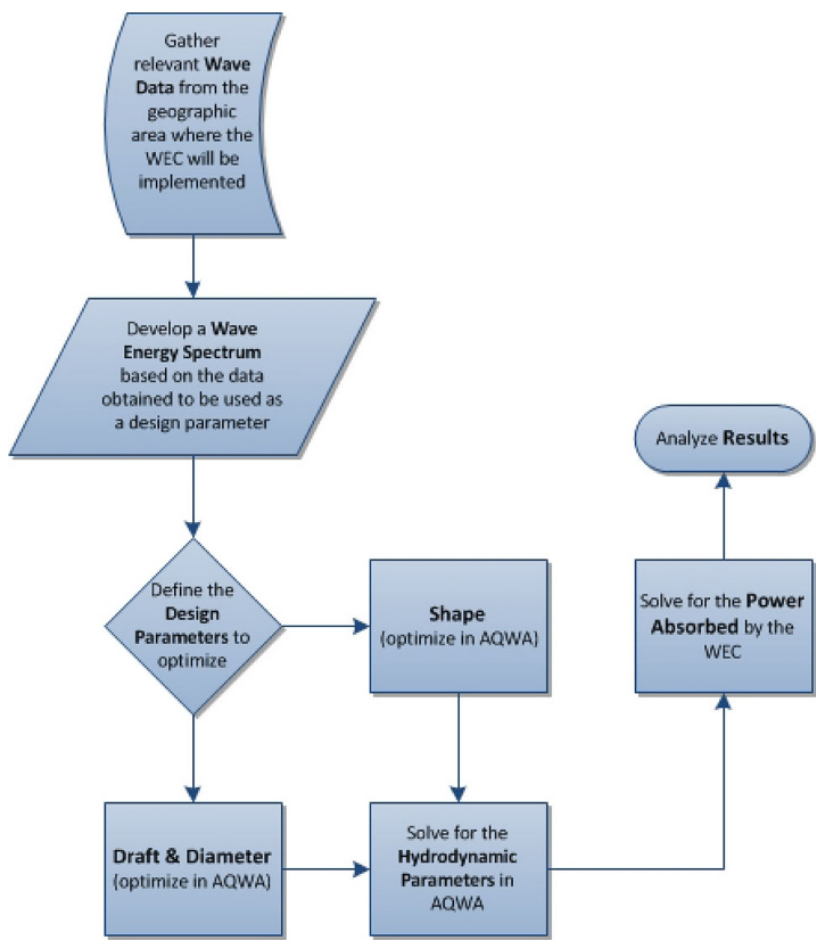

Fig. 1 Flowchart of the design optimization process

proposed method, a measured or calculated linear power capture response of the device was combined with wave spectrum to compute the average captured power function. Recently, three individual wave power generation technologies (Wave Dragon, AquaBuOY, and Pelamis) were studied and evaluated using multicriteria decision analysis through the use of the PROMETHEE method. Experimental tests were performed to collect data from the three technologies and the results showed that the data yielded from AquaBuOY technology satisfactorily meet all the design criteria [12].

To effectively use the waves near an offshore platform, a design concept is needed to be easily adaptable to the platform. Miller and Miles examined the feasibility of a practical wave energy converter using an oscillating water column and a counter-rotating turbine on a fixed offshore platform [13]. However, from our preliminary study, it was concluded that a point absorber is the best design suited for those offshore platforms because it is light and simple and can be easily attached to an existing offshore platform to provide at least $20 \%$ of electricity required for running that platform [2]. Thus, in this study, a point absorber designed by the authors is presented and used for modeling, analysis, and optimization. An overview of the design optimization process used in this study can be seen in the flowchart shown in Fig. 1. The point absorber concept is a form of WEC that can be compared to that of a mechanical oscillator, composed of a mass-spring-damper system with 
one degree of freedom, subjected to an external force in the direction of the degree of freedom. A similar schematic representation is shown in Fig. 2. The displayed point absorber system consists of a buoy that is restricted to heave mode only. The designed point absorber WEC can be directly installed at a fixed structure (e.g., offshore oil and gas platforms) and motion of the buoy with respect to the fixed structure is linearly damped to maximize its power absorption capacity. In this study, frequency and time domain analyses are performed to fully determine the power output of this WEC system. Figure 3 plots a

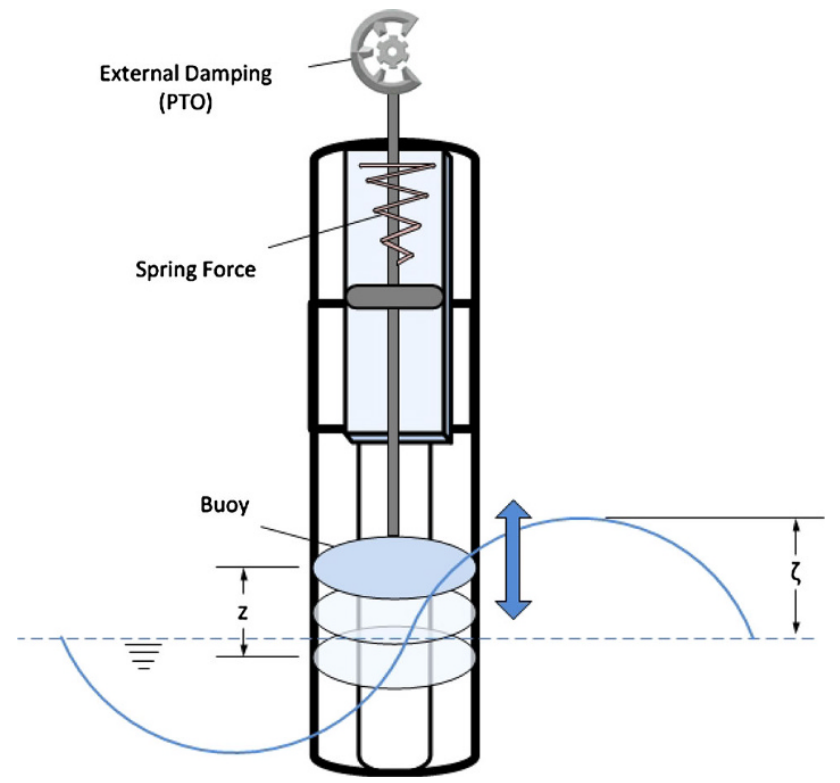

Fig. 2 Schematic representation of a heaving point absorber with applied spring control force flowchart illustrating how to combine the two types of analysis to estimate the output power.

\section{Frequency domain modeling and analysis}

Numerical model

Using linear theory, the equation of motion of a floating body, oscillating in heave mode is written as:

$m \frac{\mathrm{d}^{2} z}{\mathrm{~d} t^{2}}=F_{\text {ex }}+F_{\text {rad }}+F_{\text {res }}+F_{\text {damp }}+F_{\text {tun }}$

The PTO forces associated with this system are the damping force $F_{\text {damp }}$, which is caused by the force of the generator on the floating body, and the tuning force $F_{\text {tun }}$ caused by the spring forces used to tune the system. These forces are assumed to be linear and the floating body is allowed to respond to the harmonic excitation forces $\left(F_{\mathrm{ex}}\right.$, $F_{\text {rad }}$, and $F_{\text {res }}$ ) caused by the wave. This gives our equation an analytical solution. The excitation force as well as the radiation force is the primary force that defines impulse response functions (IRFs). The two forces are defined by:

$F_{\text {ex }}(t)=\int_{-\infty}^{\infty} \eta(\tau) f_{\text {ex }}(t-\tau) \mathrm{d} \tau$

$F_{\text {rad }}(t)=\int_{-\infty}^{t} f_{\text {rad }}(t-\tau) \dot{x}(\tau) \mathrm{d} \tau$

where $F_{\mathrm{ex}}(t)$ is found by the convolution of the water surface elevation, $\eta(t)$ with the non-casual IRF, $f_{\mathrm{ex}}(t)$. Second, $F_{\text {rad }}(t)$ is caused by radiating waves and is
Fig. 3 Flowchart of a WEC dynamic model

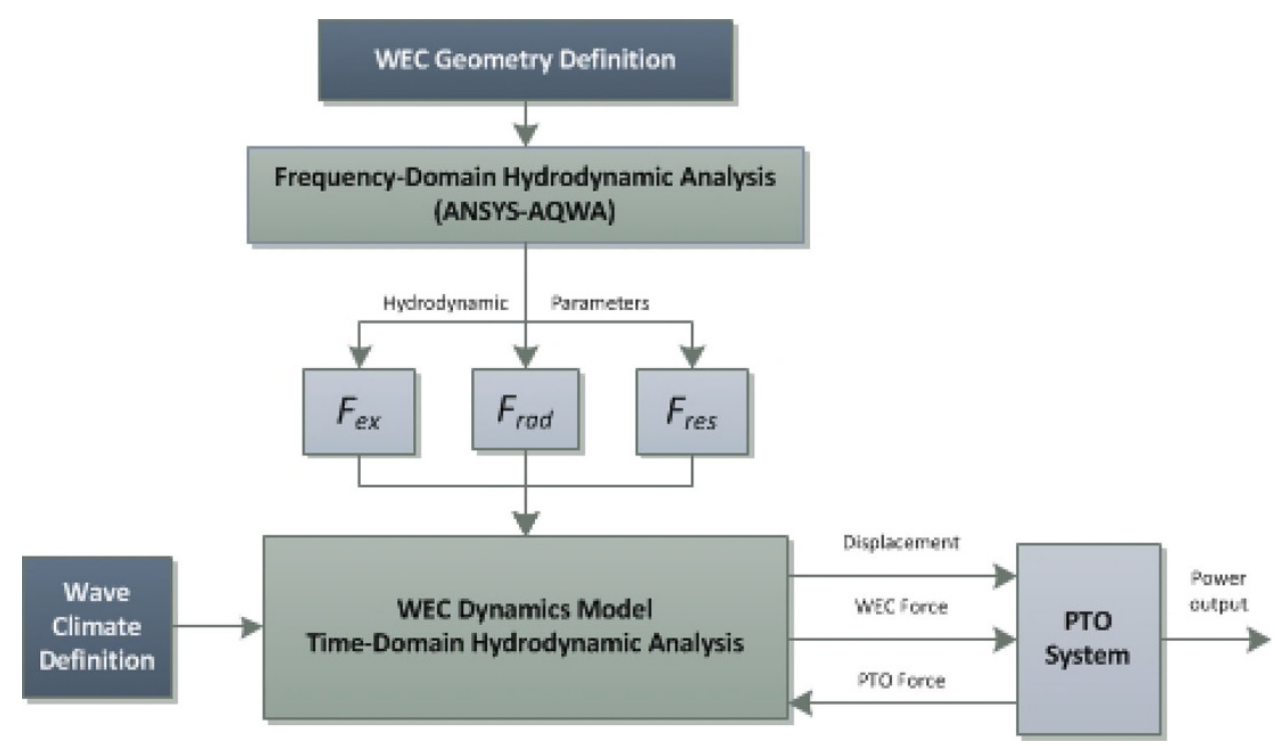




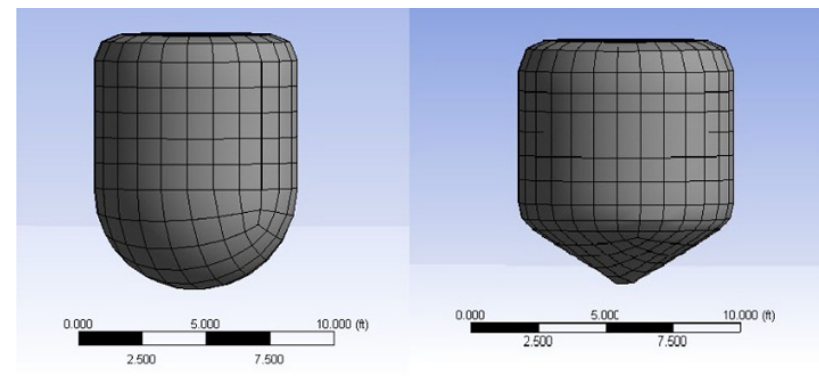

Fig. 4 The two buoy shapes considered in this study: hemispherical and conical shape

determined by the convolution of the radiation IRF, $f_{\mathrm{rad}}(t)$, with the WEC's velocity.

Next, the frequency domain excitation force $f_{\mathrm{ex}}(i \omega)$, is used to calculate the time domain excitation IRF, $f_{\mathrm{ex}}(t)$, the frequency domain radiation $f_{\mathrm{rad}}(\omega)$ is used to calculate the time domain radiation IRF, $f_{\mathrm{rad}}(t)$, and the limit at infinity of the frequency domain added mass is evaluated, $F_{\text {res }}(\infty)$. These hydrodynamic terms, $f_{\mathrm{ex}}(t), f_{\mathrm{rad}}(t)$, and $F_{\text {res }}(\infty)$, are the building blocks of the time domain WEC equations of motion (EOM). These time domain EOM use the IRF formulation and were first introduced by Cummins for ship motions in 1962 [14].

$f_{\mathrm{ex}}(t)=\frac{1}{2 \pi} \int_{-\infty}^{\infty} f_{\mathrm{ex}}(i \omega) e^{i \omega t} \mathrm{~d} \omega$

$f_{\mathrm{rad}}(t)=\frac{2}{\pi} \int_{0}^{\infty} f_{\mathrm{rad}}(\omega) \cos (\omega t) \mathrm{d} \omega$

In the frequency domain, the equation of motion of the point absorber, subjected to a harmonic excitation with angular frequency $\omega$, can be formulated as:

$$
\begin{aligned}
F_{\text {ex }}(\omega, t)= & \left(m+m_{\mathrm{a}}(\omega)+m_{\text {sup }}\right) \frac{\mathrm{d}^{2} z(t)}{\mathrm{d} t^{2}} \\
& +\left(b_{\text {ext }}+b_{\text {hyd }}(\omega)\right) \frac{\mathrm{d} z(t)}{\mathrm{d} t}+k z(t)
\end{aligned}
$$

where $z(t)$ is the complex amplitude of the buoy position and $F_{\text {ex }}$ is the complex amplitude of the heave exciting force. The mass of the buoy is denoted by $m$, the added mass by $m_{\mathrm{a}}$, the hydrodynamic damping coefficient by $b_{\text {hyd }}$ and the hydrostatic restoring coefficient by $k$. The force associated with the external damping coefficient $b_{\text {ext }}$ has to be exerted by the PTO and is called the damping force. A spring force term is added to the equation to realize a tuning force proportional with the buoy. This tuning force can also be realized by means of a supplementary mass term $m_{\text {sup }}$. The hydrodynamic parameters $m_{\mathrm{a}}, b_{\text {hyd }}$ and $F_{\text {ex }}$ are dependent on both the buoy shape and wave frequency

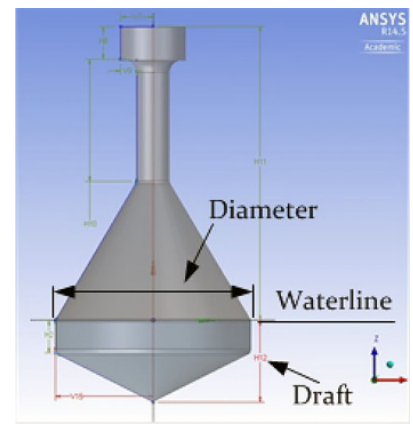

Fig. 5 Buoy draft and diameter descriptions

Table 1 Sea state values used for calculation

\begin{tabular}{lll}
\hline Sea state & $H_{\mathrm{s}}(\mathrm{m})$ & $T_{\mathrm{p}}(\mathrm{s})$ \\
\hline 1 & 0.25 & 6.70 \\
2 & 0.75 & 6.70 \\
3 & 1.25 & 6.70 \\
4 & 1.75 & 7.40 \\
5 & 2.25 & 8.11 \\
6 & 2.75 & 8.81 \\
7 & 3.25 & 8.81 \\
8 & 3.75 & 9.52 \\
\hline
\end{tabular}

and are calculated with the boundary element method (BEM) software package AQWA [15].

Hydrodynamic parameters

Shape In this study, two buoy shapes are considered: a conical shape with an apex angle of $120^{\circ}$ and a hemisphere, both are extended by a cylindrical part (Fig. 4). In the framework of the current project, some additional shapes have been evaluated, among them a tulip-like shape and a number of cylindrical shapes with a small draft.

Draft and diameter Simulations are run for eight different waterline diameters (D) ranging between 1.5 and $6.5 \mathrm{~m}$. For each buoy diameter, three different drafts are evaluated corresponding to a submerged cylindrical part of $2,2.5$, and $3 \mathrm{~m}$. Figure 5 gives an overview of the considered buoy with a description of the diameter and draft.

Wave climate Eight reference sea states are used in this study for evaluating the power output capacity of the WEC system (Table 1). In Table $1, H_{\mathrm{s}}$ is the significant wave height and $T_{\mathrm{p}}$ the peak wave period. As shown in Table 1, the first sea state covers $H_{\mathrm{s}}$ values from 0.00 to $0.50 \mathrm{~m}$, the second sea state covers the range between 0.50 and $1.00 \mathrm{~m}$, and so on. The combination of $H_{\mathrm{s}}$ and $T_{\mathrm{p}}$ is representative for the North Sea area. The considered reference water depth is $50 \mathrm{~m}$. The data tabulated in Table 1 come from [8]. Please be advised that the wave data of the North Sea 
Fig. 6 Added mass of the conical and hemispherical buoy with a diameter of $3.5 \mathrm{~m}$ and a draft of $2 \mathrm{~m}$

Fig. 7 Radiation damping of the conical and hemispherical buoy with a diameter of $3.5 \mathrm{~m}$ and a draft of $2 \mathrm{~m}$
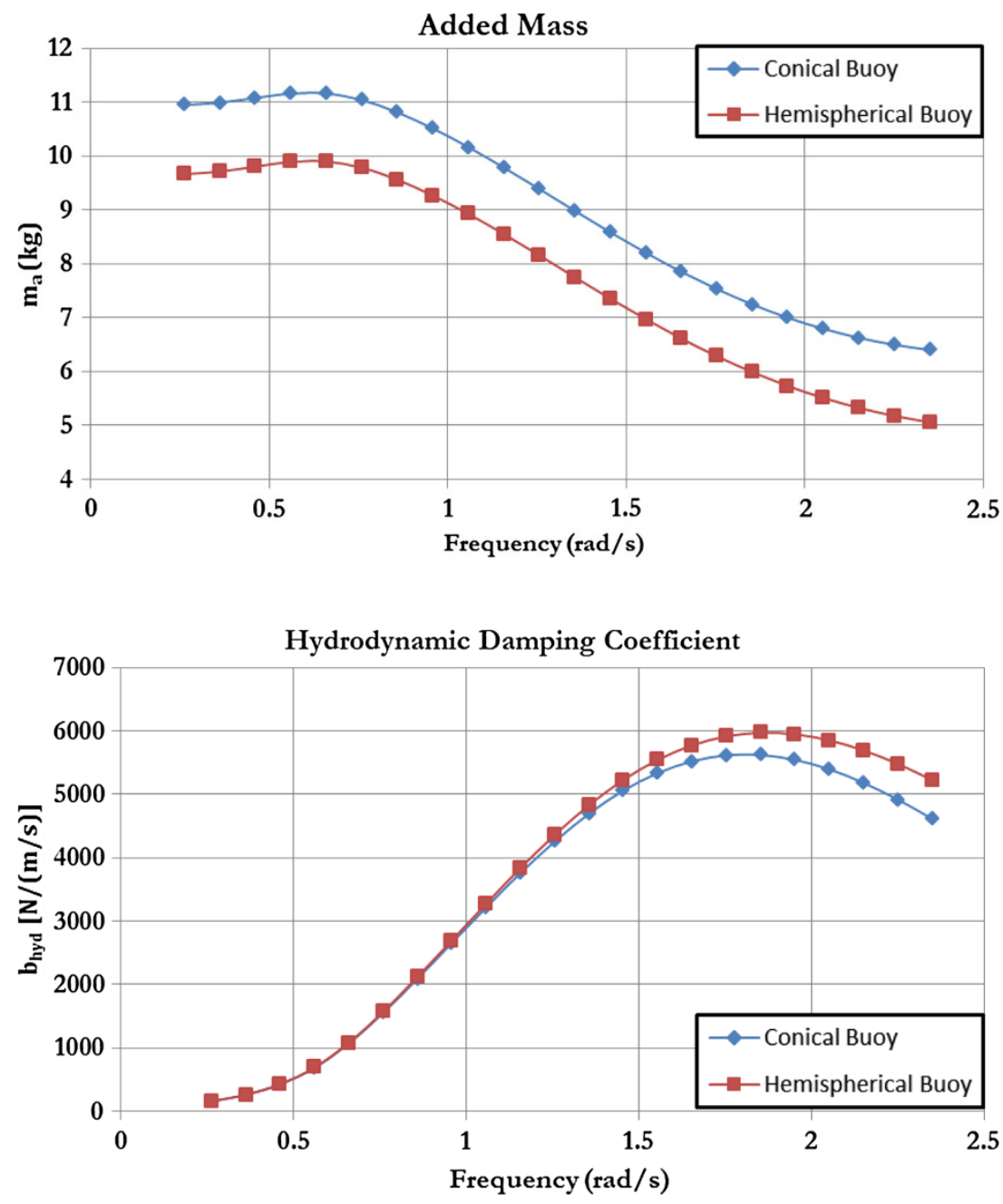

Fig. 8 Heave excitation force of the conical and hemispherical buoy with a diameter of $3.5 \mathrm{~m}$ and a draft of $2 \mathrm{~m}$

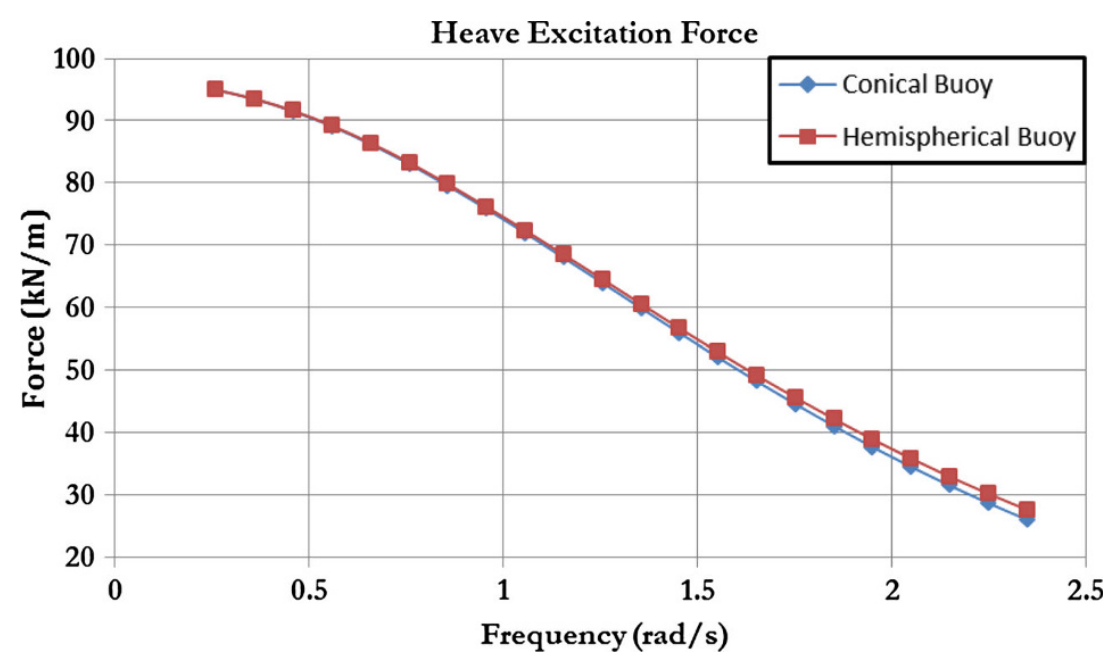

Figures 6, 7, 8 and 9 show the hydrodynamic parameters of a cone-cylinder and a hemispherical-shaped buoy with waterline diameter $D=3.5 \mathrm{~m}$ and a draft of $2.0 \mathrm{~m}$ versus the frequency bandwidth relevant to cover the spectra of are used here because that the data in the Gulf of Mexico are not available and it is believed that the sea states listed in Table 1 include a range of $H_{\mathrm{s}}$ and $T_{\mathrm{p}}$, which can also be detected from the Gulf of Mexico. 
Fig. 9 Phase angle of the conical and hemispherical buoy with a diameter of $3.5 \mathrm{~m}$ and a draft of $2 \mathrm{~m}$
Phase Angle

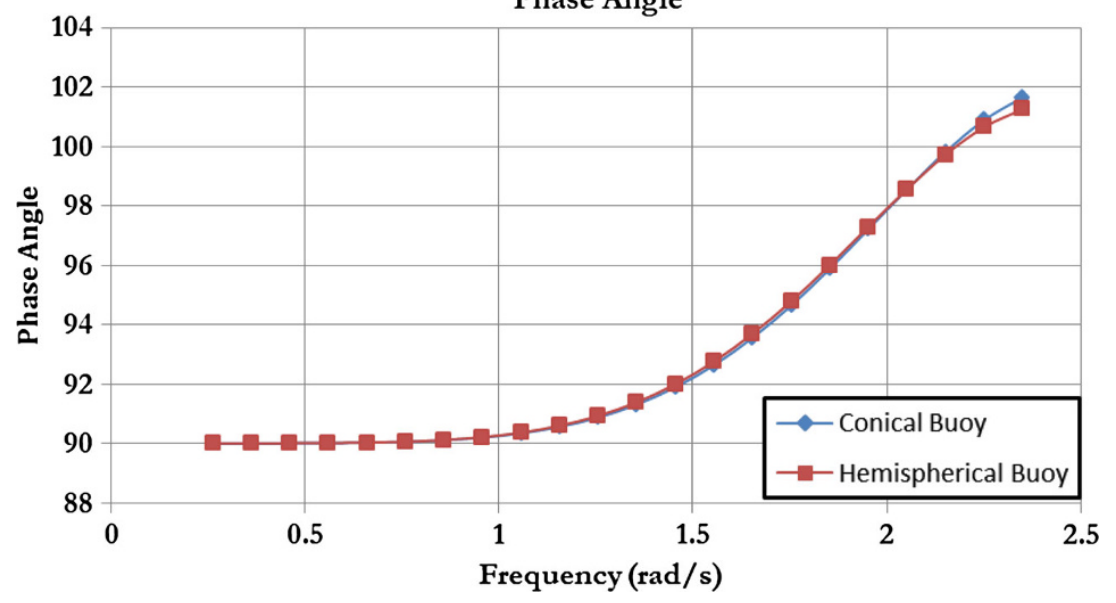

the above defined sea states. When comparing the added masses with different drafts, it was noted that a smaller draft is associated with a larger added mass in the frequency range. This was also observed for the hydrodynamic damping coefficient and the amplitude of the heave exciting force, as presented in Figs. 8 and 9, respectively. This feeds the supposition that a conical-shaped buoy may result in a larger power absorption, which will be further verified in next section. For the zero frequency limit of the heave exciting force, a value of approximately $11 \mathrm{kN} / \mathrm{m}$ is obtained with ANSYS. This corresponds to the value of the hydrostatic force per unit displacement: $\rho g A_{w}$, with $A_{w}$ the waterline area $\left(=\pi r^{2}\right)$.

\section{Power absorption}

The response in irregular long-crested waves is obtained by superimposing the responses in regular waves. The wave amplitude of those regular wave components $\left(\zeta_{A}\right)$ is derived from the Jonswap wave spectrum $\left(S_{\zeta A}\right)$ provided in ANSYS:

$\zeta_{A}=2 \sqrt{S_{\zeta A}(\omega) \Delta \omega}$

The spectrum has been covered by 20 equidistant frequencies, ranging between 0.2626 and $2.5849 \mathrm{rad} / \mathrm{s}$ with $\Delta \omega=0.09 \mathrm{rad} / \mathrm{s}$. For comparison, Vantorre et al. [16] applied the superposition principle with 20 frequencies and Ricci et al. [17] with 75 frequencies. It has been observed that with boundary conditions properly applied, simulations based on 20 frequency components are reliable. The buoy resonates and its response is overestimated for supplementary mass values corresponding to a natural period that is equal to a discrete frequency component close to the peak frequency in the spectrum. Hence, the power absorption peaks are observed at natural frequencies of the system, which do not occur if the spectrum is composed of a larger number of frequencies with smaller $\Delta \omega$. In the latter case, the power absorption varies smoothly for varying supplementary mass.

The spectrum of the amplitude of the floater position is defined as:

$S_{z A i}(\omega)=S_{\zeta A i}(\omega) \frac{z_{A i}^{2}}{\zeta_{A i}^{2}}$

Assuming Rayleigh distribution of the floater motion amplitudes, some characteristic values can be obtained such as the significant amplitude of the buoy motion:

$z_{A, \text { sig }}=2 \sqrt{\int_{0}^{\infty} S_{z A i} \mathrm{~d} \omega}$

In regular waves, the available power over the diameter $D$ of the point absorber is expressed by [18]:

$P_{\text {avail }, D}=D \int_{0}^{\infty} \rho g C_{g}(\omega) S_{\zeta}(\omega) \mathrm{d} \omega$

where $C_{\mathrm{g}}$ is the group celerity and $\rho$ is the water density. The absorbed power in a regular wave is given by Eq. 11:

$P_{\text {abs }, \text { reg }}=\frac{1}{2} b_{\text {ext }} \omega^{2} z_{A}^{2}$

where $b_{\text {ext }}$ is the linear external damping coefficient originating from the PTO system and enabling power extraction. By applying linear superposition of the buoy responses, expression for the power absorption in irregular waves can be obtained as:

$P_{\mathrm{abs}}=\int_{0}^{\infty} b_{\mathrm{ext}} \omega^{2}\left(\frac{z_{A}}{\zeta_{A}}\right)^{2} S_{\zeta}(\omega) \mathrm{d} \omega$

The absorption efficiency, $\eta$, is defined as the ratio of the absorbed power to the incident wave power within the device width: 
Fig. 10 Buoy shape analysis of conical and hemispherical buoy

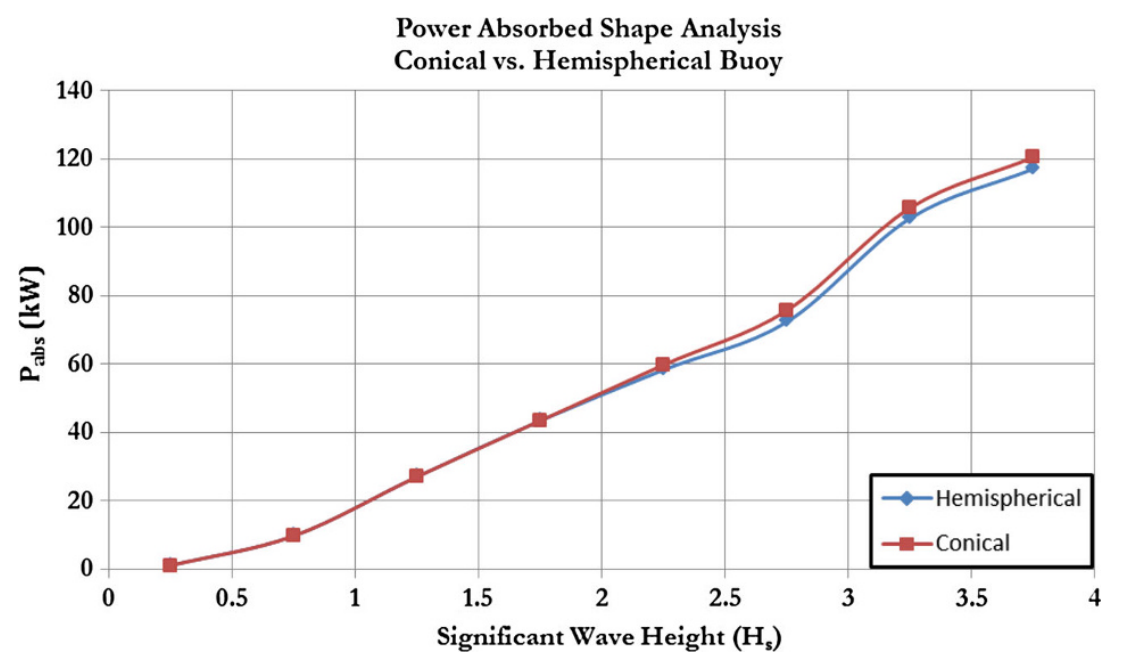

$\eta=\frac{P_{\mathrm{abs}}}{P_{\mathrm{avail}, D}}$

The absorbed power, and hence the efficiency, are influenced by the external damping coefficient $b_{\text {ext }}$, and the buoy velocity, which is dependent on both $b_{\text {ext }}$ and $m_{\text {susp. }}$. These two parameters have to be optimized to maximize the power absorption, taking into account several constraints. The optimization is carried by testing different values for $b_{\text {ext }}$ and $m_{\text {susp }}$ with a starting wave height of $0.25 \mathrm{~m}$ and a starting peak wave period of $6.70 \mathrm{~s}$ until a reasonably close value to $100 \%$ in power efficiency was achieved (Fig. 13). These values of $b_{\text {ext }}$ and $m_{\text {susp }}$ then remained constant during the course of the analysis while testing the efficiency throughout the remaining $H_{\mathrm{s}}$ and $T_{\mathrm{p}}$ values from Table 1.

Optimal buoy shape and draft

To determine an optimized design, the effects of shape and draft of the WEC on its power absorption capability were inspected using AQWA based on Eqs. 11 and 12. Figure 10 shows the comparison of the power absorbed by a conicalshaped and a hemispherical-shaped buoy at different sea states listed in Table 1. Those buoys have the same diameter of $3.5 \mathrm{~m}$ and the same draft of $2 \mathrm{~m}$ from the water line. As shown in Fig. 10, there was no significant difference in power absorption capacity between the two shapes. However, the performance provided by the conical-shaped buoy was slightly better than the hemispherical-shaped buoy. Thus, the conical-shaped buoy was selected for this study and would be used for further analysis.

While maintaining the same diameter of $3.5 \mathrm{~m}$, different results were obtained and compared for different drafts of $2,2.5$, and $3 \mathrm{~m}$. The minimum draft of $2 \mathrm{~m}$ was selected to maintain stability and robustness in the buoy under the forces acting on it from the waves as well as from the PTO system. Multiple results including power absorption $\left(P_{\text {abs }}\right)$ and absorption efficiency $(\eta)$ were compared as functions of the significant wave height $\left(H_{\mathrm{s}}\right)$ and its associated peak wave period $\left(T_{\mathrm{p}}\right)$. The $H_{\mathrm{s}}$ and $T_{\mathrm{p}}$ values used for this analysis coincide with the values used when assessing wave climate analysis, as defined in Table 1 . The results are displayed in Fig. 11, and were proven to be similar to the results observed when assessing the effects of the buoy shape. As shown in Fig. 11, for the lower sea states, the results were roughly the same but as the sea states increased the smaller draft seemed to perform slightly better than the larger drafts. Thus, the draft of $2 \mathrm{~m}$ was selected for this design and would be used for further analysis in this study. It needs to be mentioned that when converting the absorbed wave power to electrical power, extra losses need to be taken into account due to mechanical friction, viscous losses, and turbine or generator losses in the conversion system.

\section{Optimized buoy diameter}

The impact of the buoy diameter was also inspected in this study following the same approach. As mentioned in previous sections, conical buoys with draft of $2 \mathrm{~m}$ and different diameters ranging from 1.5 to $6.5 \mathrm{~m}$ with equal increment of $1 \mathrm{~m}$ were analyzed using AQWA. Here, the maximum diameter was set as $6.5 \mathrm{~m}$ because a too large buoy will be very costly in manufacturing and even may not be suited for being used on platforms due to its size. The same sea states listed in Table 1 were assumed. After simulation, the power absorption and efficiency of those conical buoys were calculated and plotted in Figs. 12 and 13 as a function of the significant wave height $\left(H_{\mathrm{s}}\right)$. From Fig. 12, it can be seen that the diameter has a significant effect on the absorbed power. As the diameter increases, the power absorbed by the buoy also increases. However, a 
Fig. 11 Power absorption of the conical buoy with drafts of $2,2.5$, and $3 \mathrm{~m}$

Fig. 12 Power absorption of the conical buoy with a draft of $2 \mathrm{~m}$ and diameters ranging from 1.5 to $6.5 \mathrm{~m}$
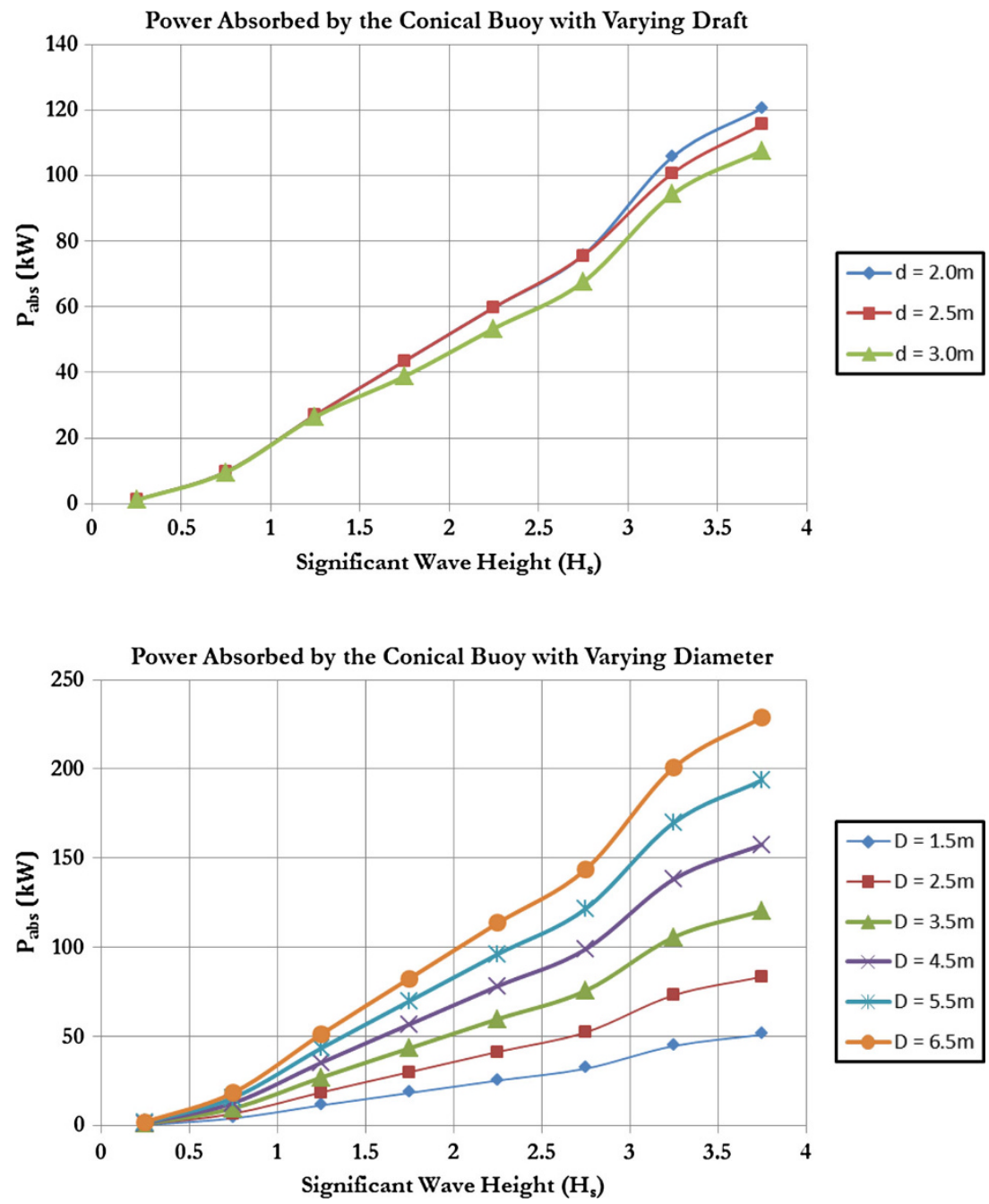

large diameter will consequently increase the overall size of the buoy and a buoy that is too large may dramatically increase the manufacturing cost. Another factor is the day to day operations that an offshore platform is involved in. This can equate to the constant boat traffic around the platform's base that allows for operations such as personnel transfer as well as crane operations for the delivery of cargo and supplies. Any additions to the platform cannot interfere with these operations limiting the placement of the technology. The only likely scenario would be to add the technology directly underneath the platform. This also can become restrictive as space is needed for riser applications and other platform fundamentals that contribute to the platforms vital functions. Another factor that must be considered is the federal safety law that governs platform operations [23]. These put in place certain restrictions on equipment to ensure safe operations to personnel and environment. Taking into consideration all these factors, the largest diameter that subjected to the economical and operational constraints and can still be effectively used on the offshore platform should be selected for building the buoy. Figure 14 shows us a typical fixed leg offshore platform and the area most suited for WEC deployment. Based on manufacturing estimates, ease of maintainability, and a best fit for the space shown in Fig. 14, a buoy diameter of $3.5 \mathrm{~m}$ was selected as the largest usable and most optimal size. With this diameter, multiple buoys can be utilized which added together can make up for decrease in diameter.

In calculating the efficiency as explained in last paragraph of "Power absorption", the tuning of the external damping force $\left(b_{\text {ext }}\right)$ and the supplemental mass $\left(m_{\text {sup }}\right)$ for each diameter have to be set at an optimal value that can lead to highest efficiency at the sea state $1(\geq 95 \%)$. This value for $b_{\text {ext }}$ and $m_{\text {susp }}$ then remains constant during the following subsequent sea states as described in Table 1. By doing this, we will be able to observe the systems' reaction in changing sea climates. As shown in Fig. 13, it can be found that the efficiency for each diameter remained almost the same. It is also observed that the efficiency calculated 
Fig. 13 Efficiency of the conical buoy with a draft of $2 \mathrm{~m}$ and diameters ranging from 1.5 to $6.5 \mathrm{~m}$
Fig. 14 Water-line profile of a fixed leg offshore platform

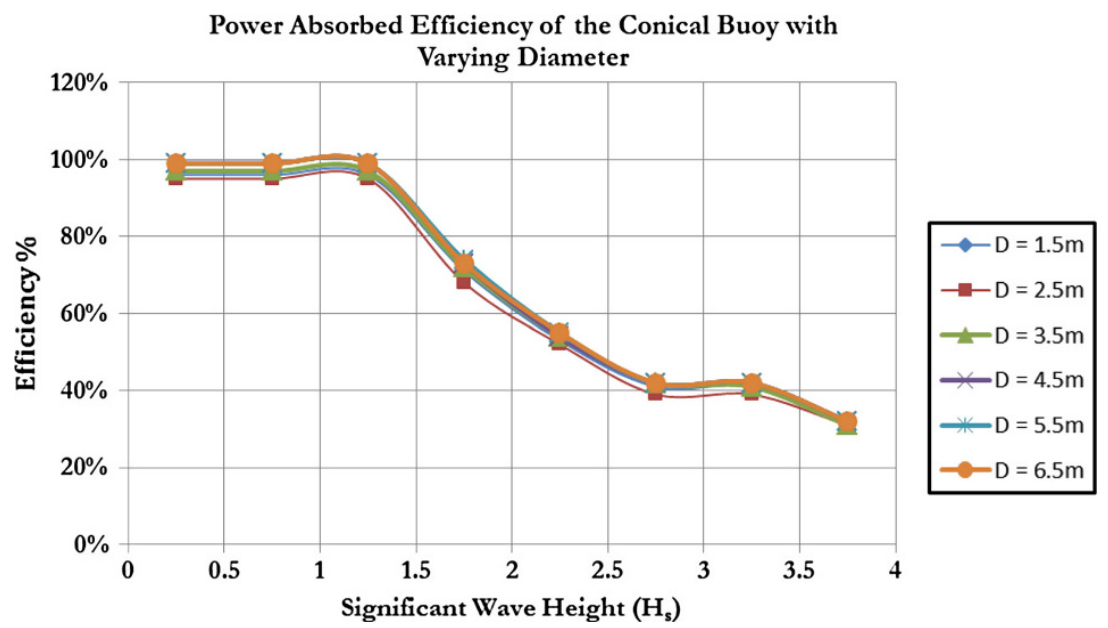

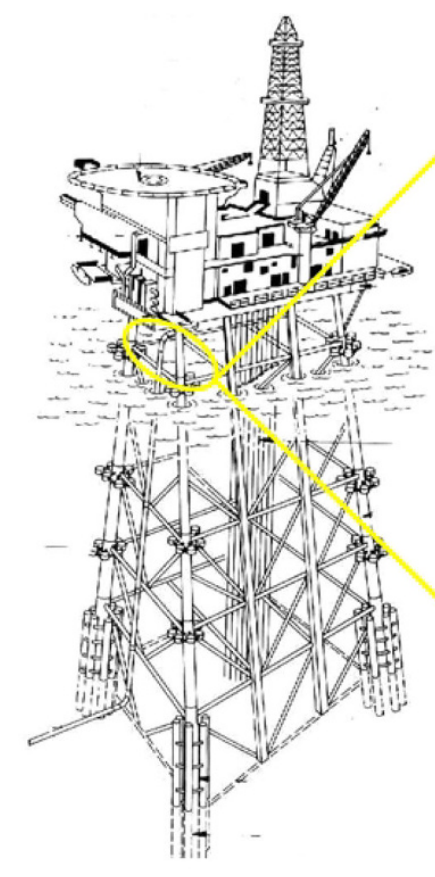

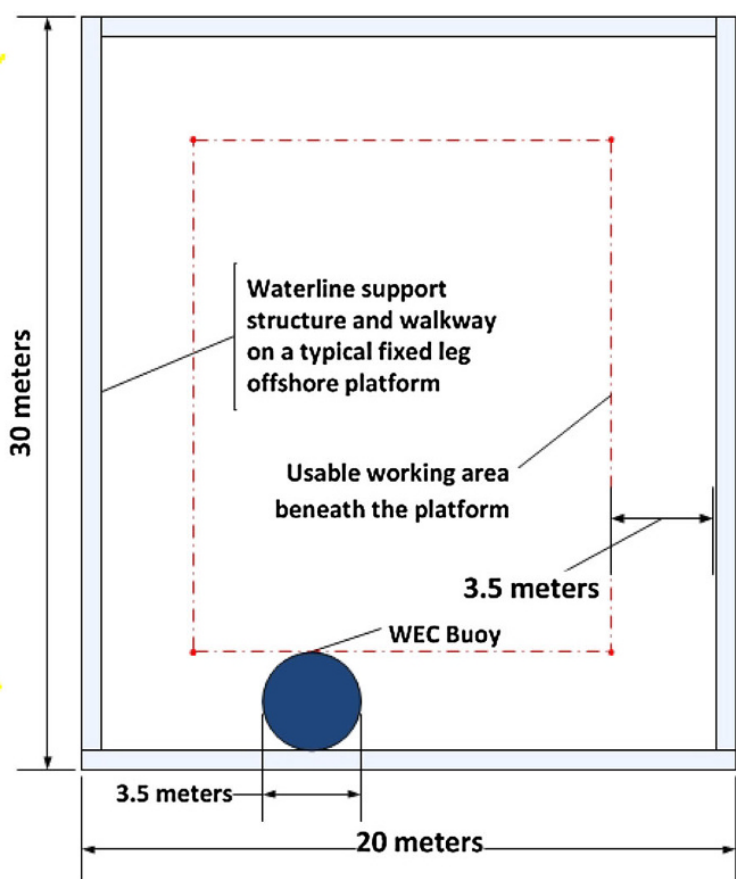

from sea state 1 to 3 (when $H_{\mathrm{s}}$ varies from 0.25 to $1.25 \mathrm{~m}$ ) is the same and the efficiency obtained from the sea state 6 equal to that calculated from the sea state $7\left(H_{\mathrm{s}}\right.$ equals to 2.75 and $3.25 \mathrm{~m}$, respectively). From Table 1, it is found that the peak period $\left(T_{\mathrm{p}}\right)$ keeps the same for the sea state 1-3 and the state 6 and 7. Thus, it can be deduced that the efficiency is correlated with the peak period, external damping force, and the supplemental mass. Therefore, when selecting and designing a PTO system, the external damping force that exerts on the system must be optimized to maximize the power absorption efficiency and should also adjust itself for the changing peak wave period.

Phenomena reflected from Figs. 10, 11, 12, 13 and 14 were also observed by Backer et al. [19]. The accuracy of the presented frequency domain numerical modeling and analysis was therefore verified. An optimized conicalshaped buoy with dimensions is displayed in Fig. 15.

\section{Time domain modeling and analysis}

Compared to the frequency domain analysis, time domain analysis allows researchers to view the reactions of a WEC system in a time period. The response amplitude operator (RAO) of the buoy position is defined as the ratio between the displacement amplitude of the uncontrolled buoy, responding to a harmonic excitation, and the incident wave amplitude [20]. It has been computed with the time domain model from the steady state response of the buoy to a regular incident wave. A window of $20 \mathrm{~s}$ was 


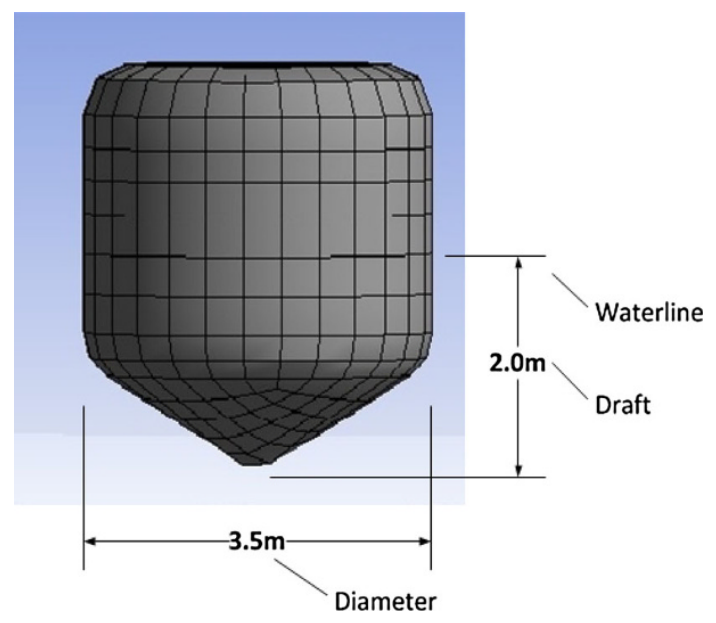

Fig. 15 CAD drawing of a conical buoy with an example diameter $3.5 \mathrm{~m}$ and draft $2 \mathrm{~m}$

used to visualize the reactions of the buoy. 120 time steps were involved in the calculation and the time domain analysis results consisted of the total force and actual position of the buoy over the period of $20 \mathrm{~s}$. For example, Figs. 6, 7, 8 and 9 display the RAO results for a buoy whose diameter is $3.5 \mathrm{~m}$, which were calculated using ANSYS AQWA.

The resulting buoy forces acting on the WEC system are displayed in Fig. 16. The maximum force acting along the positive heave direction is $6.9 \mathrm{kN}$ and the maximum force along the negative direction is $5.5 \mathrm{kN}$. Thus, an average force of $4.1 \mathrm{kN}$ is created on this system. The position of the buoy with respect to time is shown in Fig. 17. The maximum value for the buoy along the positive heave direction is $0.83 \mathrm{~m}$ and the minimum value is about 0 . That figure also reveals that during the time period, the buoy held an average speed of $0.75 \mathrm{~m} / \mathrm{s}$ (that average speed was calculated as the total distance the buoy traveled/20-s time period).

\section{PTO system and power output}

PTO system

To fully implement and apply the developed WEC system, a PTO system with high efficiency, high reliability, low maintenance cost, and reduced Cost-of-Energy (CoE) needs to be designed. Considering the offshore conditions and climate, a point absorbing WEC with a direct drive PTO system is the most efficient and beneficial in converting the low-speed oscillating motion of Gulf of Mexico (GoM) waves [2].

In this paper, a hydraulic and direct drive PTO system is presented. This system consists of a buoy attached to a rod and hydraulic cylinder, which acts as a single or double acting reciprocating piston pump. The rod of the hydraulic cylinder is forced up and down by a floating buoy, which moves fluid through check valves, rectifying the flow to a hydro-turbine or a hydraulic motor. After evaluating economic issues and performance, a horizontal axis hydrokinetic turbine device which is engaged by the heaving point absorber is considered a better fit [2].

In a study performed by the National Renewable Energy Laboratory (NREL), a design that had reasonable and validated power extraction performance was demonstrated. The PTO system comprised of commercially available offthe-shelf components and a design that can be manufactured and maintained with standard protocols [21]. The presented PTO system in that study was a $0.55 \mathrm{MW}$, horizontal axis hydrokinetic turbine device utilized in the NREL study and is applied for our heaving point absorber (Fig. 18).

\section{Power output}

The rated capacity for a turbine defines its operating parameters and the amount of power it can produce. The operating parameters of the horizontal axis hydrokinetic
Fig. 16 Resulting force of a heaving buoy over a 20 -s window
Resultant Buoy Force in the Heave Direction vs.

Time

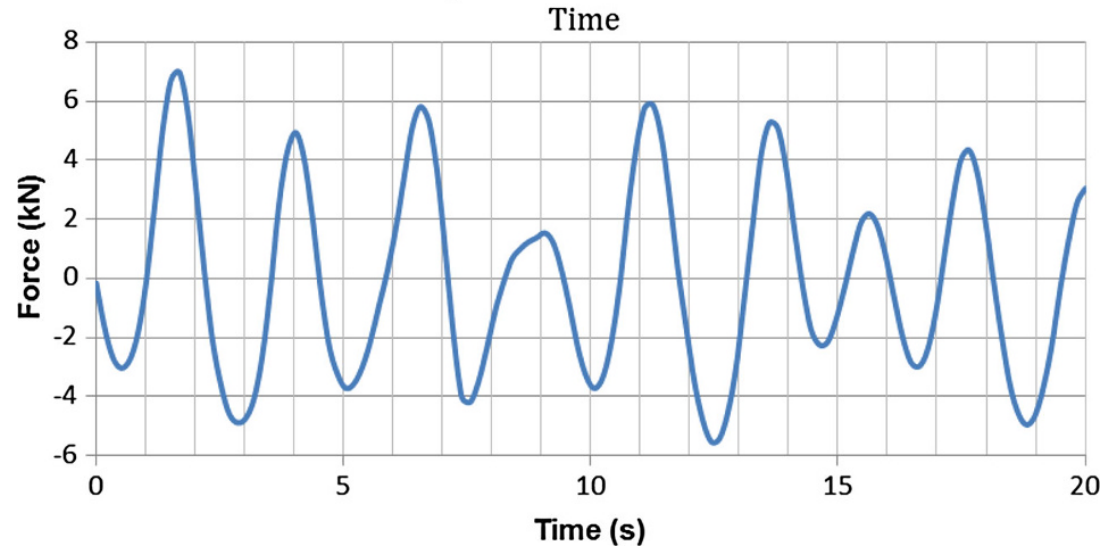


Fig. 17 Position of a heaving buoy in the heave direction over a 20 -s window

Fig. 18 A heaving point absorber WEC with a direct drive PTO system
Position of the Buoy in the Heave Direction vs.

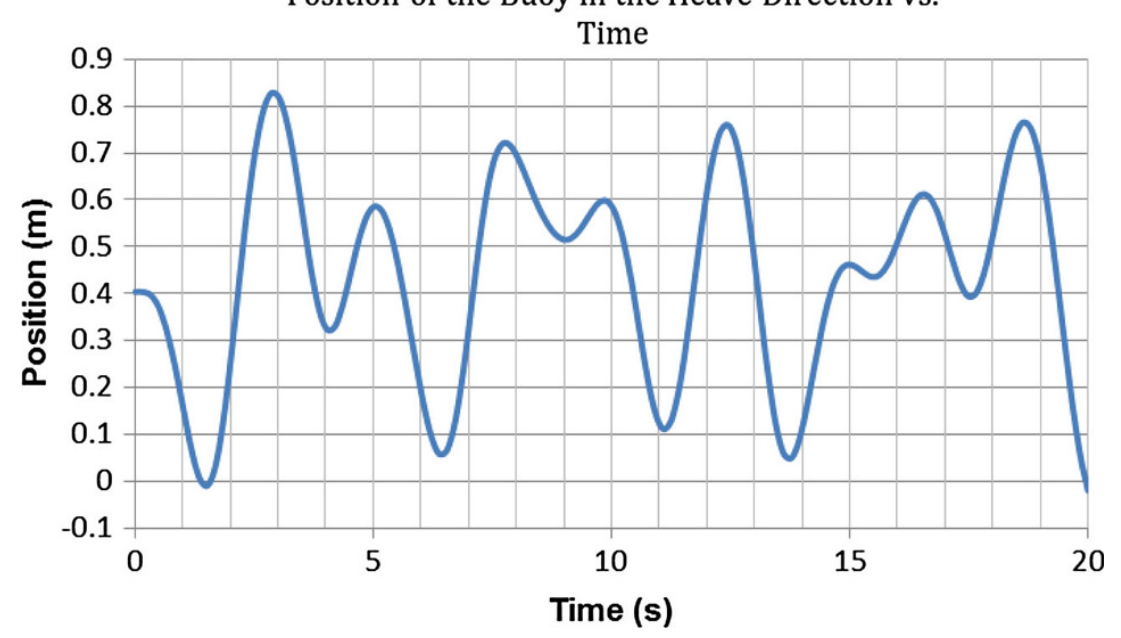

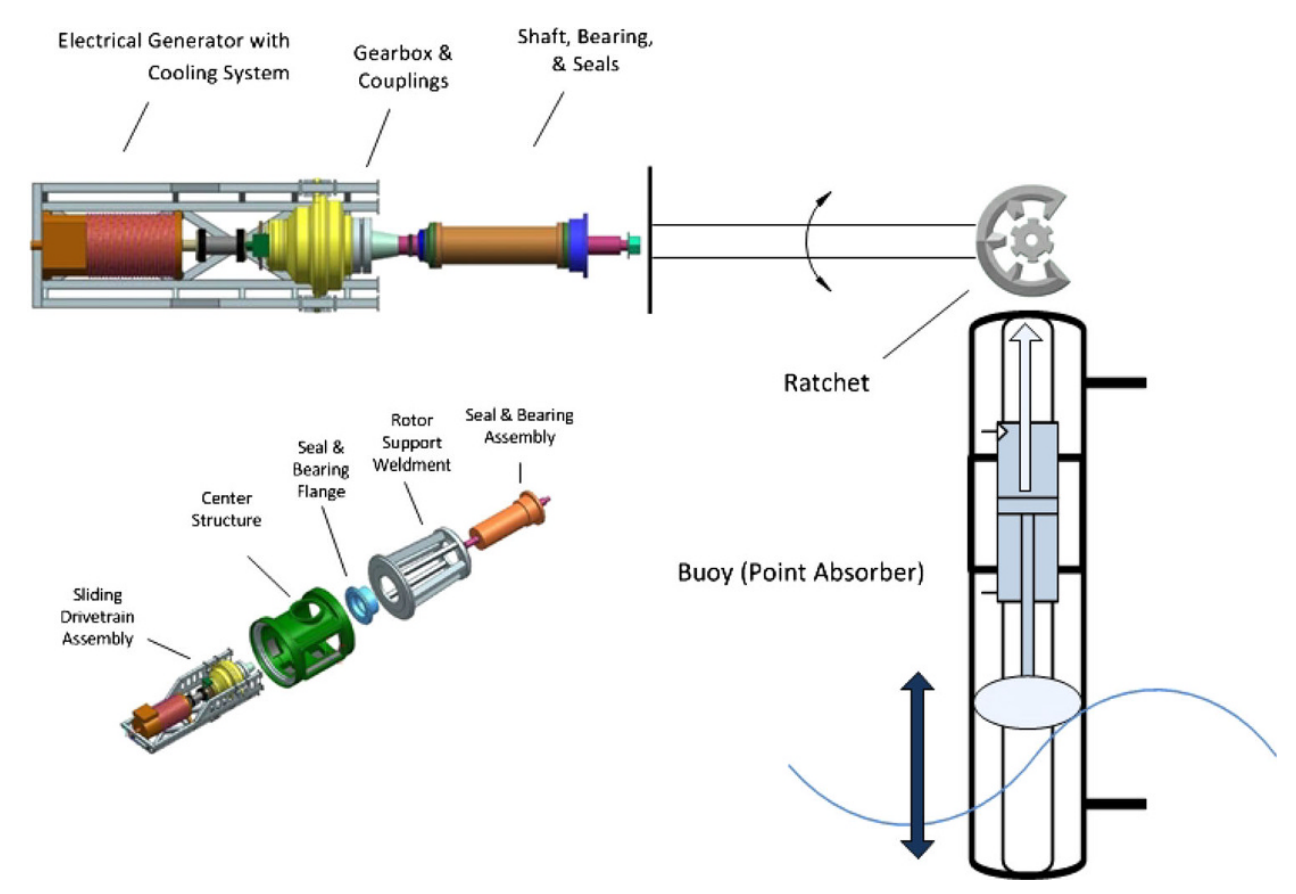

Table 2 Operating parameters of the horizontal axis hydrokinetic turbine

\begin{tabular}{ll}
\hline Operational parameters \\
\hline Max power & $550 \mathrm{~kW}$ \\
Max WEC velocity & $2.7 \mathrm{~m} / \mathrm{s}$ \\
Shaft speed & $11.5 \mathrm{rpm}$ \\
\hline
\end{tabular}

turbine used in the PTO design are listed in Table 2 [22]. As calculated from the time domain analysis, the average speed of the buoy is $0.75 \mathrm{~m} / \mathrm{s}$ and the average force is about $4.1 \mathrm{kN}$ at the given sea state. Assuming a linear power curve for the generator at the given sea state, the system will produce an average of $150 \mathrm{~kW}$ from a single buoy. This value was found by taking the percentage of the average buoy velocity $(0.75 \mathrm{~m} / \mathrm{s})$ with respect to the WEC velocity max as listed in Table 2 . This percentage was then applied to the maximum power capacity found in Table 1 and formulated as:

$$
\begin{aligned}
P W R_{\text {wec }} & =\frac{V e l_{\text {avg }}}{V e l_{\max }}\left(P W R_{\max }\right) \\
& =\frac{0.75 \mathrm{~m} / \mathrm{s}}{2.70 \mathrm{~m} / \mathrm{s}}(550 \mathrm{~kW}) \\
& =150 \mathrm{~kW}
\end{aligned}
$$

\section{Conclusions}

By means of analyzing a designed WEC in the frequency domain, the behavior of a heaving point absorber was 
assessed and the effects of different design parameters (shape, diameter, draft, etc.) on that behavior were evaluated. The hydrodynamic parameters of the oscillating buoys were derived with ANSYS AQWA (as plotted in Figs. 6, 7, 8 and 9). Through the numerical analysis, several conclusions were drawn for design optimization of the point absorber WEC. Assuming a linear power curve for the generator, the PTO system will produce an average power of $150 \mathrm{~kW}$ from a single buoy at the given sea state. The total power output will be significantly increased if multiple buoys are used in an array.

1. The conical buoy slightly outperforms the hemispherical buoy when comparing the hydrodynamic diffraction results produced by AQWA as shown in Figs. 6, 7, 8 and 9.

2. Power absorption efficiency is affected by the peak wave period at a certain sea state. The supplemental mass and external damping force have to be adjusted to maintain the efficiency when the sea state increases.

3. The power absorption capacity is also affected by the tuning forces and external damping forces that exert on the system. To maximize the power absorption, these forces have to be tuned for the average sea state in a given geographical sea area.

4. The optimal diameter can be determined by selecting the largest diameter possible for a particular device and a particular offshore location, taking into account the relevant restrictions such as the available space underneath the platform and the constraints of material, manufacturing, and maintenance costs.

5. For smaller sea states that typically occur in the Gulf of Mexico, a conical buoy with draft of $2 \mathrm{~m}$ and a diameter as large as possible would provide the best power absorption capacity and efficiency. However, to have a complete WEC system, the PTO system needs to be selected to maximize the power absorbed and converted.

6. A time domain model (Eqs. 4 and 5) was then created based on the results of frequency domain analysis for determining the displacement (position) and resulting force of the heaving buoy. The results were applied to a hydraulic, direct drive PTO system and the output power was estimated at $150 \mathrm{~kW}$ from a single buoy.

7. If multiple buoys are used in an array, then a greater power output could be reached. For example, with a configuration of 8 buoys, a total output of $1.2 \mathrm{MW}$ will be available. That amount of power is enough to operate a single offshore platform. Also, due to the relative small size and simple, robust design of the device, the presented PTO system provides a more cost-effective way to harvest $1.2 \mathrm{MW}$ power.
All the results obtained from the frequency and time domain analysis highly agree with the numerical results obtained from Backer et al. [19], the accuracy of the developed frequency and time domain analysis method and AQWA modeling, and simulation approach was therefore validated.

Open Access This article is distributed under the terms of the Creative Commons Attribution License which permits any use, distribution, and reproduction in any medium, provided the original author(s) and the source are credited.

\section{References}

1. Pelc, R., Fujita, R.M.: Renewable energy from the ocean. Mar Policy 26(6), 471-479 (2002)

2. Pastor, J., Liu, Y.-C.: "Hydrokinetic energy overview and energy potential for the Gulf of Mexico". In: IEEE Green Technologies Conference, Tulsa, OK 2012

3. McCormick, M.E., Surko, S.W.: An experimental study of the performance of the counter-rotating wave energy conversion turbine. ASME J Energy Resour Technol 111(3), 167-173 (1989)

4. McCormic, M.E.: A theoretical analysis of a self-propelled backward-bent duct wave energy conversion system. ASME J Energy Resour Technol 113(2), 94-100 (1991)

5. Weinstein, A., Fredrikson, G., Parks, M.J., Nielsen, K.: "AquaBuOY: the offshore wave energy converter numerical modeling and optimization". In: Proceedings of MTTS/IEEE TechnoOcean'04, 1854-1859, Kobe, Japan 2004

6. Henderson, R.: Design, simulation, and testing of a novel hydraulic power take-off system for the Pelamis wave energy converter. Renew Energy 31(2), 271-283 (2006)

7. Falcao, A.F.O.: Modeling and control of oscillating-body wave energy converters with hydraulic power take-off and gas accumulator. Ocean Eng 34(14-15), 2021-2032 (2007)

8. Margheritini, L., Vicinanza, D., Frigaard, P.: SSG wave energy converter: design, reliability and hydraulic performance of an innovative overtopping device. Renew Energy 34(5), 1371-1380 (2009)

9. Ruellan, M., BenAhmed, H., Multon, B., Josset, C.: Design methodology for a SEAREV wave energy converter. IEEE Trans Energy Convers 25(3), 760-767 (2010)

10. Elwood, D., Yim, S.C., Prudell, J., Stillinger, C., von Jouanne, A., Brekken, T., Brown, A., Paasch, R.: Design, construction, and ocean testing of a taut-moored dual-body wave energy converter with a linear generator power take-off. Renew Energy 35(2), 348-354 (2010)

11. Sheng, W., Lewis, A.: Assessment of wave energy extraction from seas: numerical validation. ASME J Energy Resour Technol 134(4), 041701-041708 (2012)

12. Monds, J.R.: Multicriteria decision analysis for wave power technology in Canada. ASME J Energy Resour Technol 136(2), 021201-041708 (2013)

13. Green, W.L., Campo, J.J., Parker, J.E., Miller, J.A., Miles, J.B.: Wave energy conversion with an oscillating water column on a fixed offshore platform. ASME J Energy Resour Technol 105(4), 487-490 (1983)

14. Cummins, W.E.: The impulse function and ship motions, Report 1661 (1962)

15. AQWA-WAVE User Manual, 12.1, ANSYS, Inc., (2009) 
16. Vantorre, M., Banasiak, R., Verhoeven, R.: Modeling of hydraulic performance and wave energy extraction by a point absorber in heave. Appl Ocean Res 26, 61-72 (2004)

17. Ricci, P., Saulnier, J.B., Falcao, A.: "Point-absorber arrays: a configuration study off the Portuguese west-coast". In: Proceedings of 7 th European Wave and Tidal Energy Conference, Porto, Portugal 2007

18. Crabb, J.: Synthesis of a directional wave climate. In: Count, B. (ed.) Power from sea waves. Academic Press, London (1980)

19. De Backer, G., Vantorre, M., Banasiak, R., Beels, C., De Rouck, J.: Numerical modeling of wave energy absorption by a floating point absorber system. In: Proceedings of 17th International Offshore and Polar Engineering Conference, Lisbon, Portugal 2007
20. Falnes, J.: Ocean waves and oscillating systems. In: Linear interactions including wave-energy extraction. Cambridge University Press, Cambridge (2002)

21. Lawson, M., Li, Y., Thresher, R.: Marine hydrokinetic turbine power-take-off design for optimal performance and low impact on cost-of-energy. In: Proceedings of 32nd International Conference on Ocean Offshore and Arctic Engineering, Nantes, France, 2013

22. Melfi, M.J.: Induction versus permanent magnet motors. IEEE Ind Appl Mag 15(6), 28-35 (2009)

23. "Oil and gas and sulphur operations in the outer continental shelf". 30 CFR 250 (2014) 